
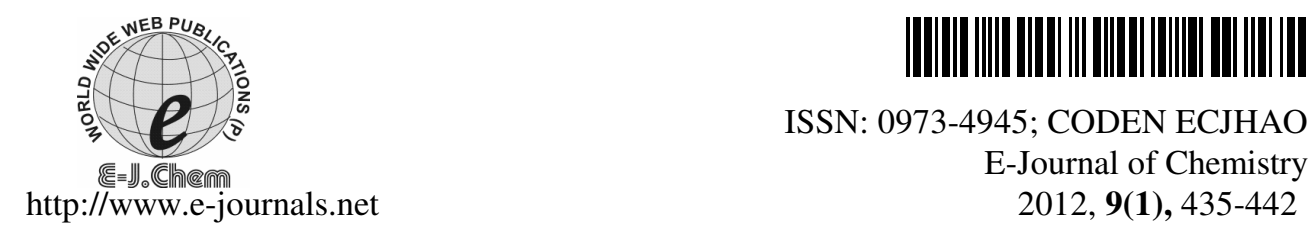

ISSN: 0973-4945; CODEN ECJHAO

E-Journal of Chemistry 2012, 9(1), 435-442

\title{
Polymeric Organo-Silane Coatings for Aluminum Alloy Corrosion Protection by Self-Assembled Method
}

\author{
YABIN WANG, YANNI LI and FANG WANG* \\ College of Science,Northwest Agriculture \& Forest University \\ XiNong Road No.22, Shannxi-Yangling, 712100, China \\ wangfang4070@nwsuaf.edu.cn
}

Received 14 November 2010; Accepted 5 December 2010

\begin{abstract}
The protective performances of coating formed by organo-silane with a linear alkyl chain for promoting aluminum alloy corrosion protection were evaluated by electrochemical techniques. The coatings were selfassembled in the hydrolyzed hydroalcoholic bath of $n$-octyltriethoxysilane (OS) and cured at hot air oven by different time. The coatings prepared by the less self-assembled number and shorter cured time, were always porous and scarcely protective. On the contrary, those built by the more self-assembled number and the longer cured time had higher coverage on aluminum surface and favorable corrosion resistant property. The best results were obtained when $n$-octyltriethoxysilane (OS) was hydrolyzed $25 \mathrm{~h}$, self-assembling of OS was conducted for five times and the multi-layers were cured at 120 for $1 \sim 2 \mathrm{~h}$. In this case, the thicker, high cross-linked and more scarcely defective layer was formed on aluminum alloy surface.
\end{abstract}

Keywords: Polymeric silane coating, Aluminum alloy, Self-assembly, Polarization curve

\section{Introduction}

Aluminum and its alloys are widely used as industrial metal materials because of their appearance, low density, high strength, easy machining and corrosion resistance. At the same time, naturally formed thin layer of aluminum oxide can prevent corrosion in mild corrosive environments. However, this layer is unable to prevent corrosion in severe circumstances. Therefore, additional coatings are required to protect the aluminum and its alloy surfaces in order to obtain higher protection levels ${ }^{1,2}$.

As natural oxide layer could not protect aluminum from the aggressive environment, chromate conversion coating was used ${ }^{3,4}$ before. Recently, the use of chromating has been heavily restricted by environmental legislations due to the high toxicity and carcinogenity of 
hexavalent chromium ions $\left(\mathrm{Cr}^{6+}\right)$. A need for an alternative anticorrosion surface treatment has thus evolved. Various organic-inorganic hybrid materials have received considerable attention as new functional material ${ }^{5,6}$. These materials are of great interest because they impart both organic and inorganic characteristics. The organic part and inorganic part are combined together by chemical bond, making the interface of two parts not clear. Incorporation of organic functional groups helps the surface of the hybrid coating material possess hydrophobic characteristics. In addition to forming dense, highly adherent layers on aluminum surface, a covalent bonding of $\mathrm{Si}-\mathrm{O}-\mathrm{Al}$ can be formed between sol-gel derived hybrid film and the surface of aluminum or steel ${ }^{7-12}$. Among them, silane surface treatment ${ }^{13}$ of metals has emerged in recent years as one of the promising alternatives for chromates in metal-finishing industries. In general, this technology includes attractive benefits such as environmental compliance, economical application and good corrosion inhibition as well as paint adhesion to a variety of metals. Van Ooij et al. ${ }^{14-16}$ studied the use of various silanebased pre-treatments for the corrosion protection of aluminum, aluminum alloys ${ }^{17}$, steel ${ }^{18}$ and iron ${ }^{19}$. Metroke et al. ${ }^{20-22}$ used EIS and salt spray analysis to determine the corrosion protective properties of hybrid organic-inorganic coatings on 2024-T3 aluminum alloys. Hydrolysis water ratio, organic content, curing mechanism and solvent dilution were found to affect the structure and corrosion resistance properties of the investigated Ormosil thin films ${ }^{23,24}$.

In the present paper, the polymeric $n$-octyltriethoxysilane (OS) films are prepared by means of dip coating and curing method on $\mathrm{Al} 5052$ substrate surface. The hydrolysis extent of OS hydroalcoholic solution was observed through electrical conductivity. The effect of dipping time, self-assembled number and curing time on polymeric OS films has been investigated. The corrosion protection performances of polymeric OS films are also studied by the polarization and cyclic voltammetry curve.

\section{Experimental}

Al 5052 alloys $(0.2 \times 50 \times 30 \mathrm{~mm})$ were provided by Northwest Institute for Non-ferrous metal research. The aluminum surface must be thoroughly cleaned. Among the various chemical treatments available, we found that degreasing by ultrasonication in an acetone bath for $10 \mathrm{~min}$, followed by treatment with an alkaline bath (3.0-vol.\% $\mathrm{AC} 1055^{\mathrm{TM}}$, Chemetall $\mathrm{GmbH}$ ) at $60{ }^{\circ} \mathrm{C}$ for $3 \mathrm{~min}$, rinsing with distilled water, drying by hot air flux and then modification by corona discharge, were the most efficient cleaning process. The aluminum surface containing functional hydroxy groups and good wettability was obtained by the process ${ }^{25}$.

The $n$-octyltriethoxysilane (97\%) was purchased from Aladdin reagent (China) Co., Ltd. The self-assembled solution consisted of ethanol, distilled-water and $n$-octyltriethoxysilane monomer $(90 / 5 / 5, \mathrm{v} / \mathrm{v} / \mathrm{v})$. The $\mathrm{pH}$ of OS hydroalcoholic solution was adjusted to fixed values (from acidic to basic) with additions of acetic and sodium acetate buffer solution. Before the filming treatment, the solutions were maintained under stirring conditions at $30{ }^{\circ} \mathrm{C}$ for a certain time to allow the hydrolysis of the alkoxy $\mathrm{Si}-\mathrm{OCH}_{2} \mathrm{CH}_{3}$ groups. Then, the pretreated $\mathrm{Al} 5052$ substrates were immersed in the hydrolyzed silane hydroalcoholic solution at room temperature for different time, rinsed with alcohol and dried with hot air flux. Successively, they were subjected to be cured at $120{ }^{\circ} \mathrm{C}$ in the air oven.

The apparatus used for all the electrochemical tests was $\mathrm{CHI} 660 \mathrm{C}$ electrochemical workstation. The cyclic voltammetry measurement was carried out by applying a $0.05 \mathrm{Vs}^{-1}$ 
scanning rate and $-0.7 \mathrm{~V} \sim 0.2 \mathrm{~V}$ scanning range. The polarization curves were measured by applying a $0.1 \mathrm{mVs}^{-1}$ sweep rate and $-800 \mathrm{mV} \sim 450 \mathrm{mV}$ sweep range. A saturated calomel electrode (SCE) was used as the reference electrode while the usual three-electrode assembly (working, counter and reference electrode) was adopted to evaluate the protective performances in the aggressive solutions $(3.5 \% \mathrm{NaCl})$ at $25 \pm 0.1{ }^{\circ} \mathrm{C}$. IR Prestige- 21 spectrometer was used to record the FT-IR reflection spectra of the polymeric OS film on Al5052 surface. The FT-IR reflection spectra were obtained using $p$-polarized light incident at $80^{\circ}$.

\section{Results and Discussion}

The self-assembled polymeric film can not be prepared on aluminum surface when the unhydrolyzed $n$-octyltriethoxysilane solution is used. However, if the hydrolysis time is too long, it will lead to produce flocculent precipitate and make the solution to be invalidated. Therefore, it is very necessary to monitor the extent of $n$-octyltriethoxysilane hydrolysis. Figure 1 shows the effect of hydrolysis time on electrical conductivity of OS hydroalcoholic solution. At the initial stage, the hydrolysis of OS will be performed according to eq. 1. With the concentration of Si-OH increasing, the conductivity of solution will be improved by the ionization reaction (eq. 2). The rate of hydrolysis is more rapid before 15 hours because of higher OS concentration. The conductivity reaches the highest value when the hydrolysis time is 24 hours. At the same time, the side reactions such as esterification (eq.3), condensation (eq.4) and deprotonation (eq. 5) will be preceded when the hydrolysis time is more than 24 hours. It will lead that the concentration of Si-OH decreases and ionization reaction (eq. 2) is driven back to the left. So, the optimal hydrolysis time of OS will be selected in the next experiment.

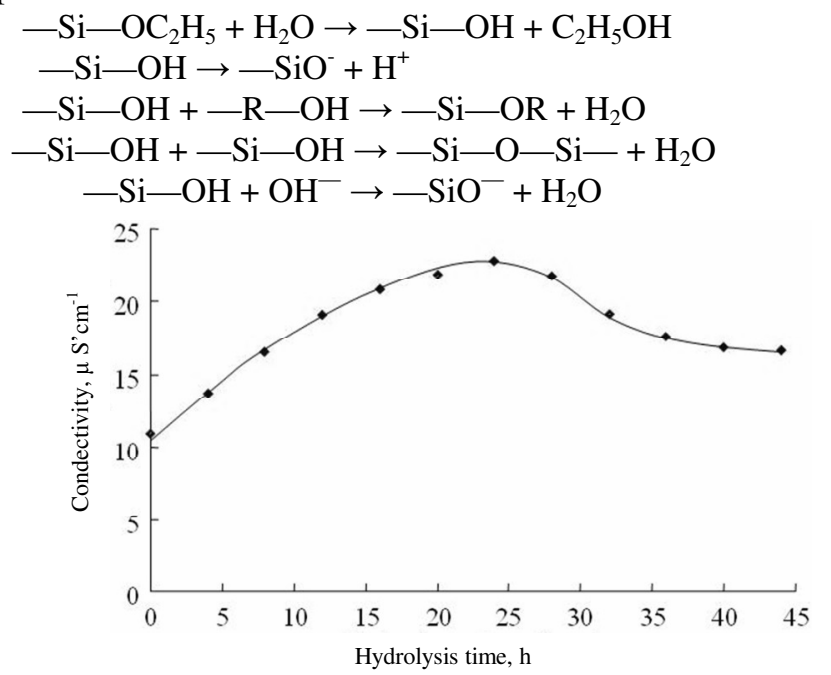

Figure 1. Effect of hydrolysis time on the electrical conductivity of OS ethanol-water solution

The structure of OS self-assembled polymeric film prepared by dip-coating method was characterized by FT-IR spectroscopy. Figure 2 shows the typical IR spectrum of OS selfassembled polymeric film on aluminum alloy surface. The appearance of adsorption bands in the $3600-3900 \mathrm{~cm}^{-1}$ regions is assigned to hydrogen bond of hydroxyl groups $(-\mathrm{OH})$. It suggests that the outside part of OS self-assembled polymeric film on Al5052 surface is non 
condensed silanol groups in the sample. The tiny weak peak at $2,972 \mathrm{~cm}^{-1}$ is due to $-\mathrm{CH}_{3}$ asymmetric stretching in - $\mathrm{OCH}_{2} \mathrm{CH}_{3}$ groups. The tiny weak peaks at 2,948 and $2,924 \mathrm{~cm}^{-1}$ belong to $\mathrm{C}-\mathrm{H}$ stretching $\left(\mathrm{CH}_{2}\right.$ and $\left.\mathrm{CH}_{3}\right)$ groups. The peaks at $1,746,1,686$ and $1,645 \mathrm{~cm}^{-1}$ are attributed to $\mathrm{C}=\mathrm{O}$ stretching vibrations. The peaks shown in Figure 2 at 1,524, 1,548 and $1,572 \mathrm{~cm}^{-1}$ are due to the formation of aluminum carbonates on $\mathrm{Al} 5052$ surface $^{26}$. The small peaks at 1,322 and $1337 \mathrm{~cm}^{-1}$ due to the $-\mathrm{Si}-\mathrm{C}$ symmetric bending in $-\mathrm{Si}\left(\mathrm{CH}_{2}\right)_{7}-$ groups and $\mathrm{C}-\mathrm{H}$ bending vibration are also detected. A broad peak between 1,120 and $1,085 \mathrm{~cm}^{-1}$ corresponding to -Si-O-Si- and Al-O-Si- asymmetric stretching, is clearly observed. It indicates that the condensation reaction has occurred between $\mathrm{AlOOH}$ of corona treated $\mathrm{Al}$ 5052 surface and $-\mathrm{Si}-\mathrm{OH}$ groups of the hydrolyzed OS. Meanwhile, a broaden shoulder at $\sim 1039 \mathrm{~cm}^{-1}$ is clearly observed. This shoulder has been related to the formation of inorganic -Si-O-Al- bonds in the interfacial layers as stated by some authors ${ }^{27}$. Recently, secondaryion mass spectrometry (SIMS) was used to directly detect the formation of Si-O-metal bonds at the interface between metals and silane films or silane-contained organic coatings. The peak at $846 \mathrm{~cm}^{-1}$ is attributed to unreacted silanol groups $(-\mathrm{SiOH})$ while the peak at $762 \mathrm{~cm}^{-1}$ is attributed to $\mathrm{Si}-\mathrm{O}$ stretching (unhydrolyzed $\mathrm{Si}-\mathrm{OCH}_{2} \mathrm{CH}_{3}$ ) groups.

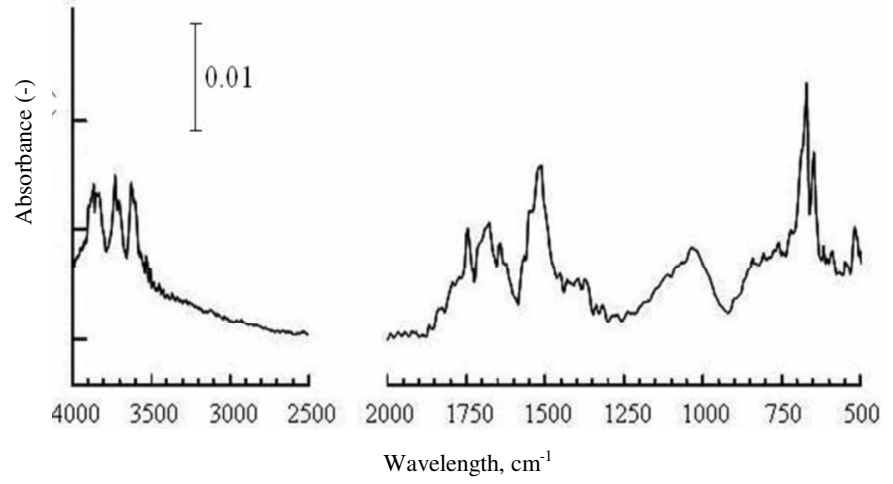

Figure 2. FT-IR spectra of Al5052 surface coated by OS self-assembled polymeric film (Resolution: $4 \mathrm{~cm}^{-1}$; Incident angle: $80^{\circ}$; Scan times: 128 times)

Electrochemical techniques like cyclic voltammetry (CV) and polarization measurements are easy techniques for monitoring self-assembled film characteristics. These electrochemical studies also provide useful information about the distribution of defects like pinholes, redox property of attached groups, kinetics and mechanism of film formation, quantitative estimate of coverage etc. Figure 3(a) and (b) shows a comparison of the cyclic voltammetry curve of bare $\mathrm{Al}$ and aluminum surfaces modified by OS self-assembled polymeric film in $3.5 \%$ aqueous $\mathrm{NaCl}$. The marked time in Figure 3(a) represents the immersion time of $\mathrm{Al} 5052$ substrate in the hydrolyzed OS solution. The marked numbers in Figure 3(b) represent the self-assembled numbers of Al 5052 substrate in the hydrolyzed OS solution and air hot oven. With the immersion time and self-assembled numbers increasing, the area in the potential range decreases. It suggests that the OS self-assembled polymeric film is formed on aluminum alloy surface, while the lack of redox behaviour indicates surface passivation. The area in the potential range is relatively larger when the immersion time is $1 \mathrm{~min}$. The result indicates that the distribution of film porosities on aluminum surface is more in the condition of the shorter immersion time. However, the areas in the potential range are almost unchanged as the immersion time is more than $10 \mathrm{~min}$. Though the areas in 
the potential range are almost unchanged with the self-assembled number increasing, the current becomes lower evidently. The result reveals that increasing the self-assembled number makes the OS self-assembled polymeric film packing on aluminum surface become denser and the film porosities decrease.

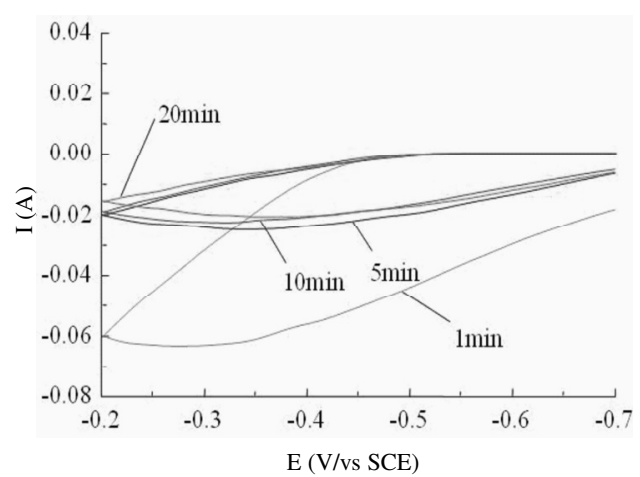

(a)

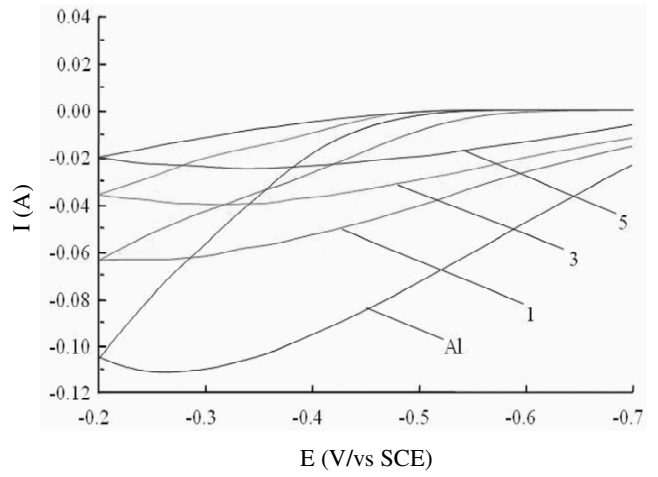

(b)

Figure 3. A comparison of cyclic voltammograms of bare $\mathrm{Al}$ and aluminum surface modified by the OS self-assembled polymeric film. (a) The curves of different immersion time; (b) the curves of different self-assembled number

Figure 4 illustrates the polarization curves, recorded for the alloys by various OS selfassembled time studied in $3.5 \% \mathrm{NaCl}$ solution. It is seen that both anodic and cathodic current densities have been largely reduced after the OS 10 min deposition compared to the bare $\mathrm{Al} 5052$ and samples treated with shorter immersion time, showing an inhibitive effect of OS self-assembled polymeric film. It is also noted that both $\mathrm{E}_{\text {corr }}$ of bare $\mathrm{Al} 5052$ and samples treated with OS for $10 \mathrm{~min}$ and the shape of the curves have not changed much. This indicates that the OS self-assembled polymeric film performs as a physical barrier rather than a chemical barrier on corona pretreated Al 5052 surface. The anodic current density is almost unchanged when the immersion time is less than $10 \mathrm{~min}$. In general, a protective silane/Al system should possess the following property from a corrosion protection standpoint. The silane film should anchor to the substrate tightly by the formation of AlOSi covalent bonds at the interface via the condensation of $\mathrm{SiOH}$ groups in the silane solution and $\mathrm{AlOH}$ groups on the $\mathrm{Al}$ surface according to:

$$
\mathrm{AlOH}_{\text {substrate }}+\mathrm{SiOH}_{\text {solution }} \rightarrow \mathrm{AlOSi}_{\text {interface }}+\mathrm{H}_{2} \mathrm{O}
$$

It is believed that the higher the density of AlOSi bonds formed at the interface, the stronger the interfacial adhesion will be between silane films and the substrate. The density of AlOSi bonds formed at the interface is lower when the immersion time is less than $10 \mathrm{~min}$. Therefore, the protectiveness of OS self-assembled polymeric film with short self-assembled time towards the substrate is weak.

AlOSi bonds at the interface, however, are not hydrolytically stable in nature. When encountered with a large amount of water, the above reaction is driven back to the left. As a consequence, the interfacial adhesion is weakened by the hydrolysis of AlOSi bonds at the interface and the silane film would then lose its protectiveness towards the substrate. Thus, improvement of water resistance of the OS self-assembled film is essential for securing the 
interfacial adhesion that is the basis for corrosion protection of the substrate. Figure 5 shows polarization curves of bare $\mathrm{Al}$ and the $\mathrm{Al} 5052$ surface modified with different selfassembled number. It is seen that the anodic current density has been largely reduced (about two order of magnitudes) and the $\mathrm{E}_{\mathrm{corr}}$ has shifted to more positive values by means of the five times self-assembly in the OS solution compared to the bare Al 5052 and samples treated with more little self -assembled number, showing an favorable inhibitive effect of OS self-assembled polymeric film. It is considered that the highly cross-linked SiOSi network is formed on $\mathrm{Al} 5052$ surface through the condensation reaction among $\mathrm{SiOH}$ groups according to:

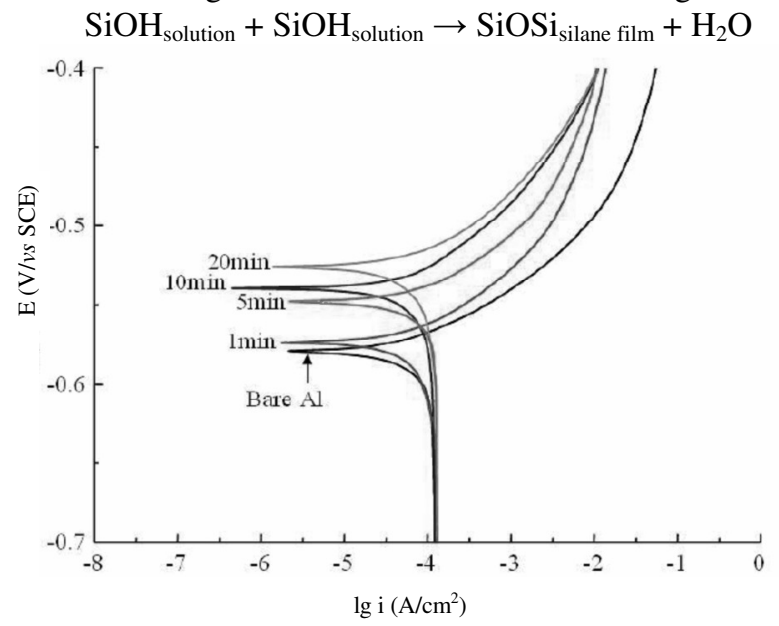

Figure 4. Polarization curves of bare $\mathrm{Al}$ and $\mathrm{Al} 5052$ surface modified by various OS selfassembled time.

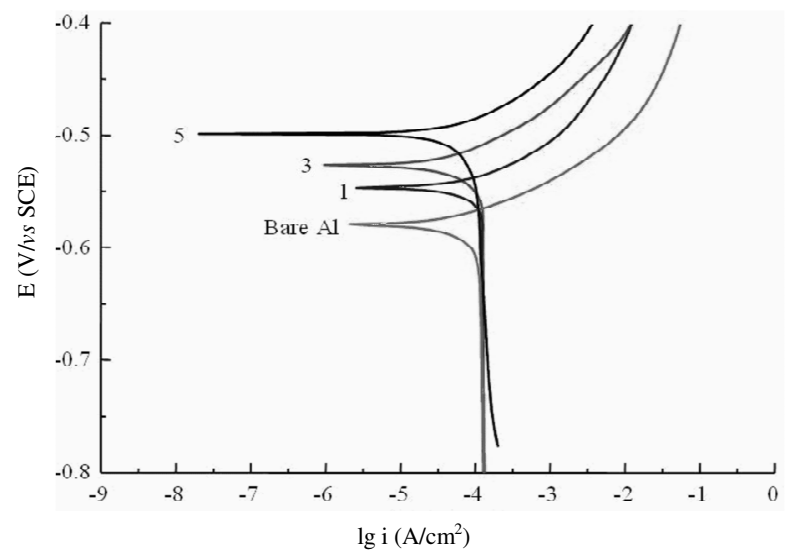

Figure 5. Polarization curves of bare $\mathrm{Al}$ and $\mathrm{Al} 5052$ surface modified with different selfassembled number

Since SiOSi units are hydrophobic in nature, a large number of so-formed SiOSi units are thus expected to contribute to the hydrophobicity of the silane/Al system. On the other hand, a highly cross-linked SiOSi network possesses a small porosity, which also hinders water penetration. So, increasing the self-assembled number can improve the degree of cross-link in the polymeric film. The high crosslinking degree of self-assembled coatings on the $\mathrm{Al} 5052$ surface makes the $\mathrm{Al} 5052$ be protected effectively. 
Certain time is necessary for the condensation reaction between hydroxyl groups. The polarization curve of samples with different curing time is measured as shown in Figure 6.

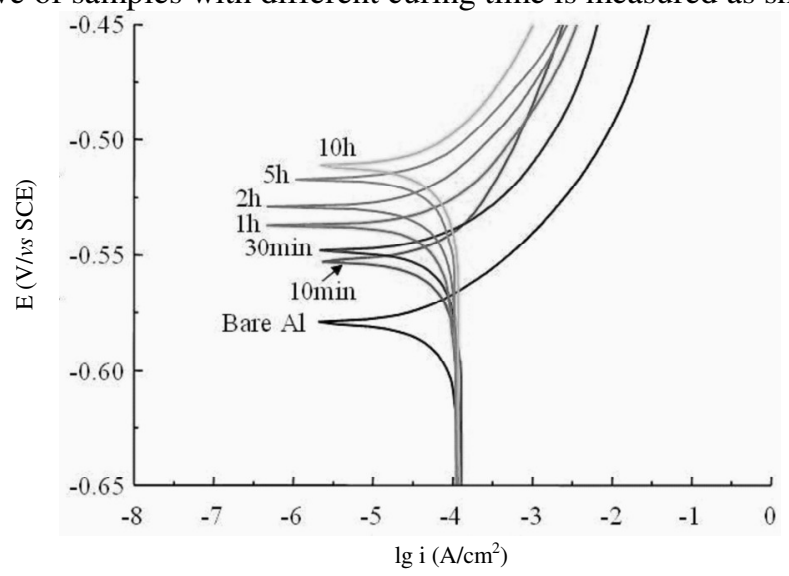

Figure 6. Polarization curves of bare $\mathrm{Al}$ and $\mathrm{Al} 5052$ surface modified by OS self-assembled polymeric film with different curing time

It is also noted that anodic current density reaches the smallest value when the sample treated by the hydrolyzed OS solution is cured for $1 \sim 2 \mathrm{~h}$. The protectiveness of OS selfassembled polymeric film towards the substrate appears poorer while the curing time is prolonged. We deduce that long time curing, except that the full condensation reaction, will lead the OS self-assembled film to be damaged and the tiny crevice to be generated. Such a film can not be expected to provide an effective barrier for the intrusion of water and dissolved corrosive species.

\section{Conclusion}

In this paper, the protective OS self-assembled polymeric film has been prepared by immersion method on $\mathrm{Al} 5052$ surface. The electrochemical measurements (cyclic voltammetry curve and polarization curves) have been conducted on $\mathrm{Al}$ alloys modified with and without OS self-assembled polymeric film. The cyclic voltammetry result reveals that increasing the self-assembled number makes the OS self-assembled polymeric film on aluminum surface become denser and the defects decrease. Both anodic current density and $\mathrm{E}_{\text {corr }}$ are found to become obviously low when the Al 5052 was treated with the OS solution for $10 \mathrm{~min}$. At the same time, the more self-assembled number also improves the protective performance towards aluminum alloy. It is considered that the highly crosslinked SiOSi network is formed on Al 5052 surface by means of increasing the selfassembled number.

\section{Acknowledgment}

The authors gratefully acknowledge Scientific Research Foundation for the Returned Overseas Chinese Scholars, State Education Ministry (No.K314020902), the Fundamental Research Funds for the Central Universities (No.A111020906) and the Scientific Research Foundation from Northwest Agriculture \& Forest University of China (No.Z111020722).

\section{References}

1. Wapner K, Stratmann M and Grundmeier G, Int J Adhes Adhes., 2008, 28(1-2), 59-70. 
2. Buytaert G, Premendra J H W, Katgerman L, Kernig B, Brinkman H and Terryn H, Surf Coat Technol., 2007, 201, 4553-4560.

3. Iannuzzi M and Frankel G, Corros Sci., 2007, 49, 2371-2391.

4. Franquet A, Terryn H and Vereecken J, Appl Surf Sci., 2003, 211(1-4), 259-269.

5. Cerveau G and Corriu R, Coord Chem Rev., 1998, 178, 1051-1071.

6. Iwona Z G, Szeluga U, Włodzimierz M, Wiesław S, Ewa B, Krzysztof H and Krzysztof M, Opt Mater., 2004, 26, 207-211.

7. Atik M, Lima Neto P, Avaca L A and Aegerter M A, Ceram Int., 1995, 21, 403-406.

8. Metroke T L, Parkhill R L and Knobbe E T, Mater Res Soc Symp Proc., 1999, 576, 293-298.

9. Guglielmi M J, Sol-Gel Sci Technol., 1997, 8, 443-449.

10. Reynolds L B, Twite R, Khobaib M, Donley M S and Bierwagen G P, Prog Org Coat., 1997, 32(1-4), 31-34.

11. Parkhill R L, Knobbe ET and Donley M S, Prog Org Coat., 2001, 41, 261-265.

12. Voevdin N N, Grebasch N T, Soto W S and ley M, Prog Org Coat., 2001, 41, 287-293.

13. Frignani A, Zucchi F, Trabanelli G and Grassi V, Corros Sci., 2006, 48, 2258-2273.

14. Van Ooij W J, Song J and Subramanian V, ATB Metall., 1997, 37, 137.

15. Van Ooij W J and Child T, Chem Tech., 1998, 28(2), 26-35.

16. Van Ooij W J, Zhu D Q, Prasad G, Jayaseelan S and Fu Y, Surf Eng., 2000, 16(5), 386-396.

17. Van Ooij W J, ATB Metall., 1998, 38, 63.

18. Sundararajan G P and Van Ooij W J, Surf Eng., 2000, 16, 315-320.

19. Subramanian V and Van Ooij W J, Corrosion, 1998, 54, 204-215.

20. Metroke T L, Kachurina O and Knobbe E T, Prog Org Coat., 2002, 44, 295-305.

21. Metroke T L, Kachurina O and Knobbe E T, Prog Org Coat., 2002, 44(3), 185-199.

22. Metroke T L, Jaspreet S G and Apblett A, Prog Org Coat., 2004, 50, 231-246.

23. Metroke T L, Parkhill R L and Knobbe E T, Mater Res Soc Symp Proc., 1999, 576, 293.

24. Metroke T L and Apblett A, Prog Org Coat., 2004, 51, 36-46.

25. Wang F, Xu J, Luo H Y, Wang J G and Wang Q, Molecules, 2009, 14, 4087-4097.

26. Nyquist R A and Kagel R D, Infrared Spectra of Inorganic Compounds; Academic Press: New York, 1971.

27. Van Ooij W J and Zhu R O, Corrosion, 2001, 57, 413-427.

28. Bandyopadhyay K, Sastry M, Paul V and Vijayamohanan K, Langmuir, 1997, 13(4), 866-869. 


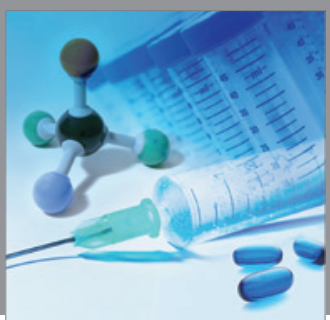

International Journal of

Medicinal Chemistry

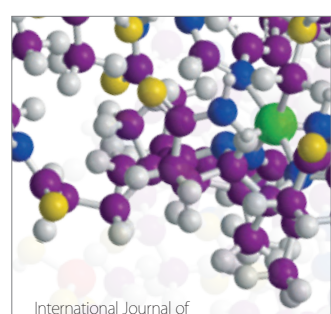

Carbohydrate Chemistry

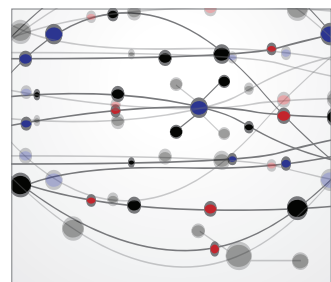

The Scientific World Journal
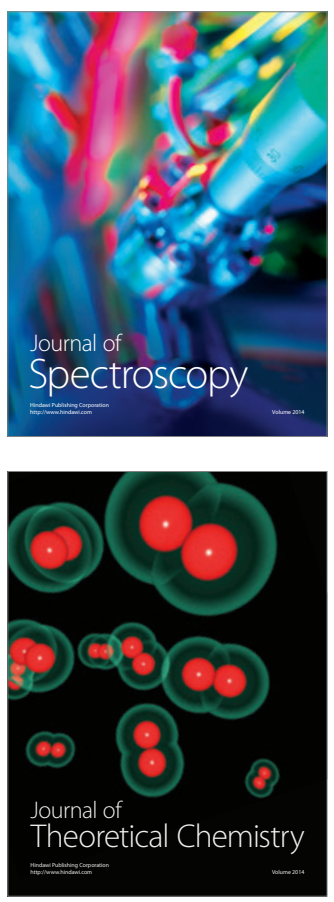
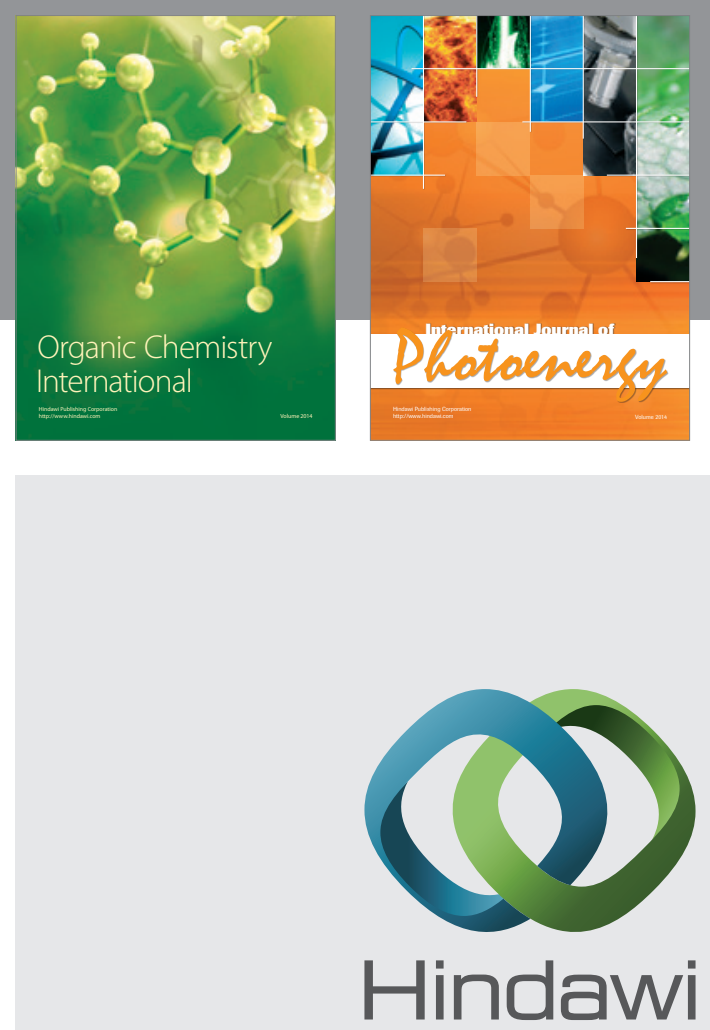

Submit your manuscripts at

http://www.hindawi.com
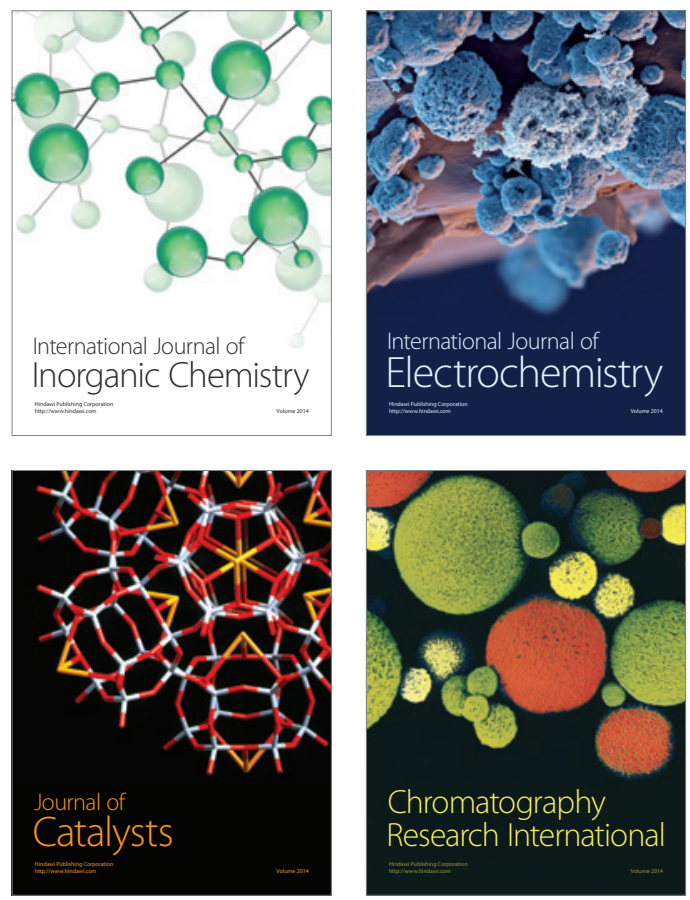
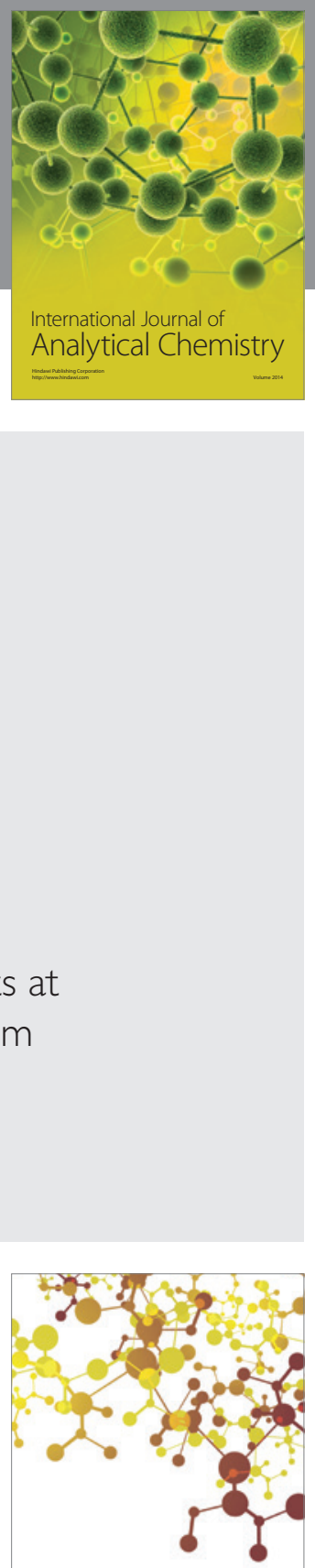

Journal of

Applied Chemistry
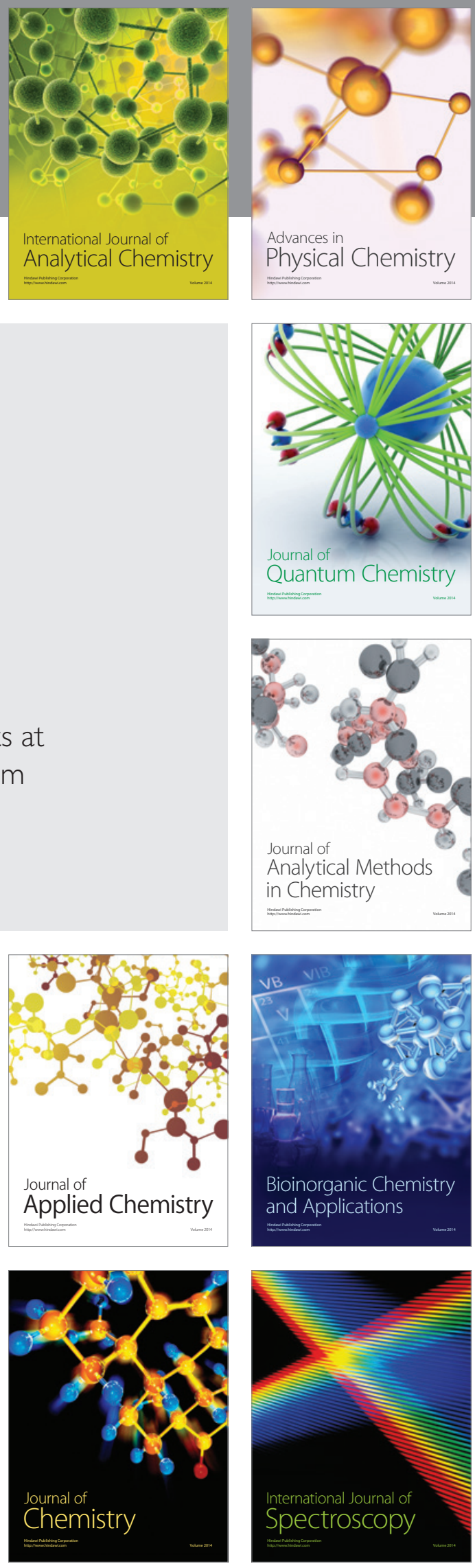